\title{
X-ray Lite: A 1-Credit Pass/Fail Crystallography Course
}

\author{
C Slebodnick \\ ${ }^{1}$ Dept of Chemistry, Virginia Tech, Blacksburg, VA \\ slebod@vt.edu
}

Single-crystal X-ray structure determination is a critical component to research programs in many science and engineering fields. Unlike other chemical characterization techniques that are commonly presented in considerable depth in undergraduate degree programs, most students receive, at best, a cursory overview of the theory of X-ray crystallography and usually zero practical experience. Whereas X-ray crystallography remains the "gold standard" of chemical structural characterization, students preparing to enter sub-disciplines where crystallography is used are at a disadvantage without at least some exposure to its underlying theory and practical methodology. X-ray Lite provides this exposure in a manner that includes hands-on "cradle-to-grave" analysis of crystalline samples, which may have originated in their own research laboratories or may be provided by the instructor. The target audience is students who use crystallography as a tool in their research and who submit samples to the Virginia Tech X-ray Service Center for analysis but are not interested in performing their own data collection and structure analysis. We thank the support of the National Science Foundation under CHE-1726077 for purchase of the diffractometer used in the hands-on portion of this course.

Acta Cryst. (2020). A76, a54 